the magnitude of those received by it. Any discontinuity of mass in the current flowing in the pipe, as for example, mercury in place of water for some part of the length of the pipe, will originate reflected or return waves. To insure good transmission, little or no discontinuity in the distribution of the inertia along the pipe should occur at any point such as would be due to changes of size or otherwise.

All these results are equally true of alternating-current circuits.

It may be shown from elementary considerations that the progressive velocity of the waves in the transmission pipe under consideration is constant for all frequencies of oscillation in case of a pipe in which the friction may be disregarded, but that the velocity increases as the square root of the frequency in any case where the inertia of the current may be disregarded. The case of the unequal velocity of the waves propagating the harmonic components of sounds in telephonic transmission by reason of their difference of pitch, which is one cause of the distortion of sound in long-distance telephone transmission, has been treated at length in the researches of Dr. Pupin who has investigated very fully the inductive (or inertia) loading necessary to render lines practically distortionless. This is equally a hydrodynamic phenomenon.

The one question remaining for elucidation is that of the attenuation or gradual diminution of amplitude of waves as they progress along the line.

It may be readily shown that in both of the two extreme cases already considered, viz., those in which either friction or inertia is disregarded, that the logarithm of the reciprocal of the amplitude, or intensity of the wave at any point, varies directly as the product of the distance of the point from the source of the wave by its velocity. Since this velocity has already been shown to be constant in case the fluid friction may be disregarded and to increase with the frequency in case the inertia is disregarded, it is evident that attenuation depends upon frequency in case of fluid friction without inertia, but it is independent of frequency in case of inertia without fluid friction. Such unequal attenuation in the telephone obliterates to a greater or less extent tones of high pitch before it does those of lower pitch. It is therefore necessary to distinct transmission that the self induction of the line should be large enough to store a large amount of kinetic and potential energy in the wave motion along the line, which in all its aspects is strictly analogous to the wave motion propagated in the water in the apparatus just described.

\section{THE CARNEGIE INSTITUTION.}

THE officers of the Carnegie Institution have appointed advisory committees and have invited suggestions from men of science. The executive committee has therefore under consideration a large number of reports and recommendations, but as these must in large measure be regarded as confidential, it is probable that the committee would welcome a public discussion of the entire question of the endowment of scientific research. ScIEnce appears to be the best place for such discussion; and it would doubtless be for the common good if those who are interested in the subject would make known their views before the meeting of the trustees in November. At that time a definite policy may be adopted, which cannot thereafter be altered. There are so many diverse possibilities and conflicting interests that these can only be sifted and reconciled by full and free discussion.

It appears that the Carnegie Institution can either undertake certain large plans for the promotion of science or can assist a great number of special researches, 
and it is probable that both methods will be adopted. The trustees will doubtless follow the principle laid down for the Smithsonian Institution by Henry and will not undertake anything that can be done equally well by other agencies. They will cooperate with existing institutions and promote new and independent centers of research, rather than establish any institution that might rival those already in existence, or undertake the control of the agencies that they may assist. Thus the Smithsonian Institution performed a service of immense value in inaugurating investigations in meteorology and fish culture and then letting these develop into the Weather Bureau and the Fish Commission. It has done work of equal importance in fostering the National Museum, the Bureau of American Ethnology and the Zoological Park, but in my opinion the time has now come when these institutions should be released from their leading strings.

It appears to me that neither of the two plans which I have heard especially discussed for the Carnegie Institution is advisable-namely, the erection of a geophysical laboratory at Washington and the acquirement of the Marine Biological Laboratory at Woods Hole. I should suppose that a geophysical laboratory at Washington would do work that might be undertaken by the Coast and Geodetic Survey and the Geological Survey, and would prevent the government from doing such work. It would seem to be better for the Carnegie Institution to employ a commission to outline the geophysical researches most needed, and then to promote them by providing equipment and making it possible for those most competent to undertake the work, always looking forward to the time when it can be handed over to the government. Even the great income of the institution, if divided among the sciences, is limited when compared with the $\$ 1,000,000$ appropriated by the government for the Geological Survey.

The acquirement of the Marine Biological Laboratory at Woods Hole is, it seems, being seriously considered by the executive committee of the institution, and this plan may therefore with advantage be discussed in some detail. It appears that the corporation has voted to transfer the laboratory to the Carnegie Institution. It was stated at the meeting of the corporation that the executive committee would recommend to the trustees the acceptance of the laboratory, the erection of buildings and an annual allowance of $\$ 20,000$. It was the preference of nearly all the members of the corporation that the laboratory should be assisted by the Carnegie Insti. tution without being made a branch of it; but the alternative was placed before them of giving away the laboratory or losing the large support of the Carnegie Institution and perhaps witnessing the establishment of a rival laboratory.

Now the Woods Hole laboratory has been dear to many biologists of the country exactly on account of its independent position and democratic organization. It is the only institution of national importance that is controlled by scientific men. There is a corporation composed chiefly of those who have carried on research in the laboratory, and this corporation elects trustees who represent different universities. The results have been what might have been anticipated from this democratic organization; there have, on the one hand, been financial troubles, and, on the other hand, there have been great enthusiasm, loyal devotion and much self-sacrifice. It seems that this is a case where the Carnegie Institution might relieve the financial difficulties without suppressing the public spirit and service of those who now conduct the laboratory. If the institution should offer 
to contribute for the present $\$ 10,000$ a year, on condition that those interested in the laboratory contribute an equal sum, the condition would be met, and the funds of the institution would go twice as far as if it assumed control. They would indeed go further; for example, the director and other scientific men serve the laboratory without salary; should a director be appointed from Washington, he would naturally expect and should receive a salary of $\$ 5,000$ or $\$ 10,000$. If the laboratory is continued as an independent institution, it will sooner or later receive adequate endowments, and the Carnegie Institution can then use its funds for other purposes. If the laboratory is made equal to the station at Naples, and nothing less has always been intended by those interested in it, an annual appropriation of $\$ 50,000$ will be required; should branches be established and an experimental farm added, this appropriation will need to be doubled, and no money would remain for purposes equally important for the advancement of biology. It seems that as a branch of the Carnegie Institution the laboratory would either be less adequately supported than if it had remained an independent institution, or it would be aggrandized at the cost of other biological laboratories, exploring expeditions, etc. In either case the centralized power of money would crush the only serious attempt of scientific men to conduct an institution for research.

The fact that the erection of a geophysical laboratory at Washington or the acquirement of the Marine Biological laboratory at Woods Hole does not seem to be the best use of the endowment of the Carnegie Institution, does not mean that the institution should not conduct any laboratory. There are undoubtedly serious difficulties in the way of simply distributing the entire income among existing institutions. These institutions might depend on subsidies rather than on their own efforts, and they might transfer to other uses funds that are now spent on the objects that the Carnegie Institution would support. It is reported that one small college has asked that its share of the fund be forwarded. As a matter of fact there are not urgent and important demands on the funds for research already existing - the Elizabeth Thompson Science Fund, the tiust funds of the National Academy of Sciences and of the Smithsonian Institution, and the research fund of the American Association for the Advancement of Science.

The Carnegie Institution can not with advantage be an Elizabeth Thompson Science Fund on a large scale; neither should it abandon its individuality to merge its income in existing agencies. The national government spends $\$ 10,000,000$ a year on its scientific departments, and universities spend annually in their various activities a much greater sum. The income of the Carnegie Institution, if merged with other agencies or made coordinate with them, would simply add 1 or. 2 per cent. to the scientific activity of the country, which is already increasing at the rate of perhaps 10 per cent. each year.

The endowment of the Carnegie Institution if invested in government bonds would yield an income of $\$ 200,000$; if invested in securities approved by the courts for trust funds, from $\$ 300,000$ to $\$ 350,000$. Perhaps one fifth of the income will be required for the expenses of administration. It may be that Mr. Carnegie will enlarge the fund; this will doubtless depend on his judg'ment as to whether or not the money is used more effectively for the public good than it could be in any other way. It seems that for the present at least one half of the income might be used to best advantage in assisting researches and existing institutions throughout the country, and in establishing new agencies that would become 
independent. The other half might be used for the establishment of an institution at Washington that would promote scientific research in a way that would not interfere with existing agencies, but would rather set them a standard.

I should like to see at Washington a Carnegie Institution somewhat on the plan of the Royal Institution of London, which, as we all know, was founded by an American. Such an institution might be made the center for the scientific life and activity of the country. The government should provide the site for the building as part of the plans for the improvement of Washington, and half the income of the institution for the next three or four years could be spent for its erection. It should contain rooms for the meetings of national and local societies, for boards and committees, and for lectures. It should contain comparatively small but admirably equipped laboratories for the three fundamental sciences-physics, chemistry and psychology.* There should be a professor or director for each of these sciences with a salary of $\$ 10,000$, whose duties it would be to conduct and direct research work in the laboratory, to coordinate and promote the research work of the country and to give a few lectures. He should have suitable assistants, computers and instrument makers at a cost perhaps of $\$ 10,000$, and about $\$ 5,000$ annually should be allowed for apparatus, with occasional special grants if needed. Efficient investigators, perhaps not more than five or six in each science, should be encouraged to carry on research in the laboratories for a year or less; these men should have leave of absence from their own institutions and would in most cases receive subsidies from

* In ranking psychology with physics and chemistry I may be influenced by the direction of my own work. I believe, however, that I am logically correct. The fact that psychology is at present more immature than physics or chemistry appears to be a reason for giving it opportunity. the general funds of the Carnegie Institution. They should give short courses of public lectures, and other men of science should be invited to present the results of their researches in lectures or articles. These should be well paid for and should not be published exclusively by the institution, but distributed freely to newspapers and journals. Then there should be a board of managers, representing each science or important branch of a science. In the exact and natural sciences there might be perhaps twenty of these managers, who would include the directors of the laboratories. With the president and secretary they should be given full and complete control of the scientific work of the institution, subject only to the veto of the board of trustees. Membership in this board of managers should be the chief distinction in American science, being conferred on those who unite eminence in research with public spirit and executive ability. The members should receive a salary of say $\$ 2,500$ a year; they should meet together at Washington for a week once a year, and perhaps should be present on one other occasion as chairmen of honorary committees on each science. Each should present a lecture or paper annually before the institution, perhaps reviewing the progress in the United States of the science that he represents. On the plan outlined the annual charge for the laboratories would be $\$ 75,000$ and for the board of managers, $\$ 50,000$. The expenses of the central institution would thus be $\$ 125,000$, to which must of course be added the cost of administration. I see no other way by which an equal sum could so effectively contribute to the advancement of science. A considerable amount of research of the highest class would proceed directly from the institution and would become quickly and widely known. The directors of the laboratories would in the character of their 
work and in their, salaries set a standard that universities and other institutions would endeavor to meet. These positions and membership in the board of managers would be a recognition of eminence and efficiency in scientific work; they would encourage men of science and make scientific work a more attractive career to young men of promise.

In connection with the central institution the question of publication should be considered. It seems to me that it would be far better to coordinate and assist existing series and journals rather than to establish new ones controlled by the institution. The present difficulties in the publication of scientific research are certainly lamentable. The proceedings of learned societies, in which subjects of all sorts are treated in a single volume, are a survival from the eighteenth century. The cost of printing, engraving and distribution, as compared with the conditions abroad, is a serious drawback to science in America. A series of monographs published by the Carnegie Institution might be of use, but would take from rather than contribute to the activity of other institutions. The publications of the Geological Survey cost $\$ 300,000$ annually, and the funds of the Carnegie Institution would go but a small way in this direction. Much more, it seems to me, would be accomplished by establishing in Washington as part of the central institution a press which would employ competent draughtsmen, engravers and proof-readers and would offer its services at such charges as are made in Germany and France. The academies of the country might then unite in publishing their proceedings in series devoted to the several sciences, and our various scientific journals could secure publication on terms as favorable as those of foreign nations. The autonomy of existing publications and their support would thus be maintained, while the fact that they came from the press of the Carnegie Institution would at a comparatively small cost contribute greatly to the prestige of the institution.

If one half the income of the institution were expended as indicated, a considerable sum would remain with which the trustees or board of managers could play the part of a special providence throughout the country. This would allow annually one or two large appropriations and a great number of smaller subsidies. It seems that the institution might in some cases with advantage give endowments rather than money for current uses. Such endowments would certainly tend to make widely and permanently known the beneficent work of the institution. The erection of a laboratory at Woods Hole, costing $\$ 100$,000 and called the Carnegie Biological Laboratory, or an endowment fund of equal amount, to be known as the Carnegie Research Fund for Biology, would in my opinion be of more value to the laboratory and to the cause of science in America than any annual subsidy. One large grant each year or two, or two or three smaller ones, either establishing permanent agencies or carrying forward projects of some magnitude, would perform an inestimable service and would stimulate and not inhibit similar gifts from other sources. Supposing the turn of psychology to come once in ten years, I can easily outline work for a century-for example, a station for the study of living animals in connection with a zoological park; a laboratory for the study of children as part of a foundling or orphan asylum; another in connection with asylums for the blind and deaf; a clinic for the psychological study of the insane; another for diseases of the nervous system and organs of sense; an expedition to collect psychological data regarding savages before they disappear; a shop where psychological instruments can be made and instrument- 
makers trained; a bureau for statistics and computations. These and other agencies would add greatly to the efficiency of existing laboratories of psychology and would in no wise conflict with them. Each could be established with a fund of from $\$ 50,000$ to $\$ 100,000$, and if made independent it would continually grow in resources and usefulness. There are doubtless in other sciences objects equally deserving and urgent, so that if the endowment of the Carnegie Institution were doubled or quadrupled the income could be used economically and advantageously.

If one half the income were expended on the central institution at Washington and one fourth on large objects, there would remain $\$ 75,000$ to $\$ 125,000$ for smaller grants and special researches. This sum could easily be spent to great advantage without interfering with other agencies.

There are certain international undertakings in which the United States should share and for which no money is available. We may hope that the general government will ultimately recognize its obligations in this direction, but for the present our national self-respect and usefulness are impaired because we can not join on equal terms with other nations. Thus we were unable to send delegates to the third conference on an international catalogue of scientific literature, with unfortunate results, as some of the measures adopted by the first and second conferences on the recommendation of our delegates were reconsidered by the third conference.* We have now no adequate means to do our share in seeing that the publications of the United States are adequately included in the international catalogue, whereas

* To give a case in which I am interested, psychology was included in the catalogue at the recommendation of Dr. Billings, but was made a branch of physiology at the third conference, when no psychologist or American delegate was present. most foreign nations have made appropriations for this purpose. In like manner we are unable to assist in the work of the Concilium Bibliographicum conducted at Zurich as an international undertaking by an American. Funds for sending delegates to the International Association of Academies were secured with much diffculty; and in general delegates to such international conferences and congresses must pay their own expenses. There are various international institutions, and more are continually being established, toward which the United States should contribute its share. In these directions the Carnegie Institution can perform large services at comparatively small expense.

There are also certain national or more local institutions which might be assisted without interfering with their autonomy, and in such a way that the aid would encourage rather than discourage other resources. The laboratory at Woods Hole appears to be the best type of these; there are numerous other marine and fresh-water stations, similar in character if less national in scope. The Blue Hill Meteorological Observatory or the Dudley Astronomical Observatory may be mentioned as examples of institutions that are doing excellent work with small resources. Should the Carnegie Institution make an appropriation on condition that it be duplicated locally, its funds would be spent to advantage.

It would be perhaps more difficult to assist directly the work undertaken by the national government, the states and municipalities, or by our richly endowed universities, observatories, museums, etc. If the funds were unlimited a laboratory of physical chemistry given to Harvard or Cornell, a needed collection given to the National Museum and the like, would certainly contribute to scientific advance; but such gifts would not be the most economical use of a limited income. There are, however, cir- 
cumstances where cooperation with other great agencies for scientific investigation might be most fertile in results. Thus, if at present the Carnegie Institution would offer to equip an antarctic expedition to cooperate with those of Great Britain and Germany, on condition that the government furnish ships and officers, the offer might be accepted. Or to take a modest case within my immediate experience-we need urgently in the psychological laboratory of Columbia University a computer who could also act as a trained subject for psychological measurements. Such computers and aids are as much needed in psychology as in astronomy, but they do not at present exist, and it is difficult to persuade the trustees of a university that this is really a pressing demand. Should the Carnegie Institution offer to give $\$ 500$ a year for three years toward the salary of a computer on condition that Columbia University contribute an equal sum, it would doubtless do so. After three years the support of the computer would probably be assumed by the university, and similar offices would be established in other universities here and abroad. In a case such as this a very small sum would contribute greatly to the advance of psychology as an experimental science. This case is given simply as an example of the way in which the Carnegie Institution could accomplish results by cooperating with existing institutions.

Two of the most important agencies for the advancement of science are societies and journals. Whatever can be done to promote their efficiency will contribute greatly to scientific progress. In many cases grants made to scientific societies might be administered more effectively than if the Carnegie Institution undertook the direct control. Thus the American Association for the Advancement of Science, with an endowment fund of about $\$ 10,000$, is able to appropriate annually about $\$ 300$ for re- search. This insignificant sum is divided among five or six committees who supervise work of importance. If the resources of the association were increased, they might under the auspices of its committees be expended more economically than direct grants from the institution. Or, to take again an example from my own science, the American Psychological Association has gradually acquired from the dues of members a fund of about $\$ 1,000$. The proposal has been made that this money be used for a psychological bibliography, which does not at present exist and is urgently needed. It is estimated that such a bibliography will cost $\$ 2,000$, and it will be necessary to wait some years before this sum will accumulate from the dues of members. Should the Carnegie Institution add $\$ 1,000$ to the equal sum in the possession of the association, it would be possible to proceed with the bibliography. The money would be spent economically, as only clerical work and printing would be paid for, while the skilled labor would be given by the association.

The great area of this country interposes a serious obstacle to scientific organization. If means could be found for paying the railway expenses of delegates to the meetings of our. national scientific societies, a forward step of great importance would be taken. I scarcely see how the Carnegie Institution could undertake this large project, but it might cooperate with societies and educational institutions in forwarding it.

In the case of scientific journals I can speak with some experience. Our scientific journals are absolutely essential to the progress of science. Those devoted to pure science are in all cases scientific and educational institutions, not commercial enterprises; most of them are in need of support and deserve it as much as universities or museums. It is, however, difficult to give such support in a useful and economic- 
al way. Thus to illustrate from the journals that I edit-ScIENce when liberally subsidized by Mr. Bell and Mr. Hubbard was conducted at an annual loss of $\$ 20,000$; The Popular Science Monthly, established in part as a commercial enterprise and fairly successful as such when the doctrine of evolution was treated as a religious rather than as a scientific question, was latterly conclucted by the publishers at an annual loss of $\$ 10,000$ and finally relinquished by them; The Psychological Review has always been published at a loss, which would be large if money were at hand to lose. I give these illustrations to indicate that if the Carnegie Institution undertook to own or control our scientific journals, the expense would be very great; whereas I believe that there would be no appreciable improvement in their contents, but, in the end, injury to the cause of science. It seems that in connection with the plan for the acquirement of the Woods Hole laboratory, the officers of the Carnegie Institution have asked for an option on the American Journal of Morphology. I trust that the institution will not undertake to own and control a journal of this character, and that those at present responsible for this journal will not abandon it. Our scientific journals should be controlled by the scientific men of the country, preferably in connection with their societies.

The fact that the Carnegie Institution should not assume control of scientific journals does not mean that it should not assist them. It will as a matter of fact do so indirectly by every action that increases the quantity or improves the quality of scientific research. I have already mentioned the great gain that would accrue if an office for printing and engraving were established that would permit the manufacture of scientific journals and books on terms of equality with foreign nations. Without direct subsidies the institution could assist in the support of scientific journals by advertising in them those of its activities that should be made public, and by subscribing for copies to be sent to the smaller libraries and institutions of learning.

In addition to such special agencies as it unay establish and to cooperation with institutions, societies and journals, the Carnegie Institution can assist directly individuals and their researches. Mr. Carnegie has specified as one of the main objects of his foundation, "To discover the exceptional 'man in every department of study whenever and wherever found, inside or outside of schools, and enable him to make the work for which he seems specially designed his life work." This as a matter of fact should be the chief function of society and has indeed been the course of nature since the beginning of organic life; but the time may now have come when we can do consciously and economically what has hitherto been done blindly and with boundless waste. It is evidently possible for the Carnegie Institution either to aid those who are beginning research or those who have already proved their ability; and it seems that both classes should be assisted in so far as the means of the institution permit.

Several university presidents have recently stated that our system of fellowships has been sufficiently extended; but in this I do not concur. It is certainly not true for my own science and my own institution. One fellowship in psychology is annually awarded at Columbia University, whereas ten could now be given with advantage, and the number needed would probably always increase in more rapid ratio than the number supplied. We can only find the exceptional man by selecting him from a considerable number who undertake research work. Those who prove themselves incompetent for important orig- 
inal investigations have not wasted their time, but are better prepared for teaching or other kinds of work. To pass beyond the limits of the already known, to discover new truth and new methods by reliance on individual initiative and judgment, to do and give and not merely learn and receive, is an educational method incomparably better than any other. Those who have accomplished this either at the university or in active life are the world's leaders. The student is in no sense pauperized because he receives a fellowship. His research is worth on the average far more than it costs ; he gives to the world more than he receives and earns his living by honest work.

If I may venture to suggest a definite plan for the award of fellowships, it would be that each university be permitted to nominate for a Carnegie fellowship, one of every ten of those on whom it confers the doctorate of philosophy. These men-who at present would number about fifteen in the sciences-would be well prepared for research and could carry it forward for a year to great advantage at Washington or elsewhere. The value of the fellowships should be $\$ 1,000$.

The Carnegie Institution will doubtless also undertake to promote scientific research by enabling men to devote themselves to investigation who have already proved themselves competent, but who are prevented by various causes from doing the work for which they are fit. The greatest obstacle to the advancement of science is, in my opinion, the circumstance that scientific men are not directly rewarded for their investigations and discoveries. The lawyer, physician or engineer can command a fee commensurate with the value of his services, the artist can sell his picture for what it is worth, the novelist receives a royalty on as many copies of his book as the public will buy; but the man of science as a rule gives his research work to the public.
He earns his living by teaching or otherwise, and is thus an amateur, not a professional investigator. In a few cases the patent office intervenes, and we see what it can accomplish, for example, in Mr. Edison's inventions. But the field covered by the patent office is small, and as a rule it is more likely to divert from than to encourage research in pure science. If some method could be devised by which society would pay the man of science even one tenth of the value of his investigations, science would enter a new era of progress. Possibly the Carnegie Institution may find some means to accomplish this end, for example, by paying an investigator for his research at the same rate that a magazine pays for a short story; but the problem is complicated and difficult. The offering of prizes is an obvious, but I fear not very satisfactory or effective, method.

I am sufficiently optimistic to believe that the combination of teaching or economic work with research is on the whole an advantage. The authorities of Columbia University expect me to give one undergraduate course with laboratory work and one advanced course with the supervision of research work. This amount of teaching, I think, improves the quality of the research work that I am able to do and does not seriously limit the quantity. Indeed the cooperation with students may increase the quantity. It would, however, doubtless be an advantage for men engaged in teaching or economic work to have occasionally a year free, devoted entirely to research, at Washington or abroad. Columbia University does not demand an excessive amount of teaching and allows a leave of absence one year in seven with half salary. Some other institutions are less fortunate or less wise, and the Carnegie Institution could accomplish results of immeasurable importance by "permitting those engaged primarily in teaching or 
economic work to devote a year to pure research. The results would extend far beyond the single year or the single individual. If the Carnegie Institution can arrange to pay half the salary of an investigator, giving him at the same time the best facilities for research at Washington, at one of our well-equipped universities or. abroad, requiring the institution with which he is connected to pay the other half, its funds would be spent wisely and economically.

There are certain men of genius or talent who for one reason or another have not been able to find a place in our organized social machinery. Such men might perform work of value if given the opportunity, and the Carnegie Institution could here assist in a way that is not possible for any other institution.

The two general principles which I have kept in mind in writing the above are that the Carnegie Institution should do (1) what it only can do, working whenever possible with existing institutions; and (2) should aim to increase the influence of men of science, working with them and through them.

The executive committee and the trustees of the Carnegie Institution will have before them reports prepared by those most competent to give advice, and their final decisions will be better considered than the views of any individual. I have ventured to print these remarks, based chiefly on the science with which I am engaged and the institutions with which I am more or less familiar, on the supposition that suggestions from all quarters will be welcomed by the officers of the institution. I have of course expressed only my individual opinions and have in no wise attempted to represent the policy of the journal in which they happen to appear. As responsible editor of this journal, however,
I urge men of science to join in a discussion of the problem as to how endowments for research, and especially the great endowment of the Carnegie Institution, can best be used for the advancement of science.

\section{J. McKeen Cattell.}

Columbia University.

SCIENTIFIC BOOKS.

Lehrbuch der Combinatorik. Von Dr. Eugen Neтto. Leipzig. B. G. Teubner. 1901. Pp. viii +260 .

At the present time neither European nor American universities offer lecture courses on the subject of combinatorial analysis. This fact is the more noteworthy when we remember that during the first quarter of the nineteenth century nearly every mathematical chair in Germany was occupied by a specialist in that field. This Combinatorial School of Germany has passed into deserved oblivion. Under the leadership of C. F. Hindenburg it represents the culmination of an unfortunate tendency of eighteenth century mathematicians to develop analysis, particularly the subject of infinite series, with reference to form only, and to pay little or no attention to the actual contents of formulæ. The polynomial theorem was hailed as 'the most important theorem of all analysis.' In combinatorial analysis (combinatoric) the German school was contented with the deduction of rules for the writing down of all the combinations and permutations that are possible under given restrictions. The simple fact that the able and fairly complete treatise now under review hardly mentions the work of Hindenburg shows that what are now considered the substantial parts of combinatoric have been developed outside of the German Combinatorial School. Associated with the early development are the great names of Pascal, Leibnitz, Wallis, James Bernoulli and De Moivre.

While combinatoric is not now made the subject of lectures in our universities, it is nevertheless of importance. The student acquires much of it during the pursuit of other branches. It is touched upon in the study 